OPEN ACCESS

Edited by:

Christopher McPherson, Washington University School of Medicine in St. Louis, United States

Reviewed by: Paola Lago,

Ca' Foncello Hospital, Italy Manon Ranger. University of British Columbia, Canada

*Correspondence: Vibhuti Shah Vibhuti.Shah@sinaihealth.ca

tThese authors have contributed equally to this work and share first authorship

$$
\begin{array}{r}
\text { Specialty section: } \\
\text { This article was submitted to } \\
\text { Pediatric Pain, } \\
\text { a section of the journal } \\
\text { Frontiers in Pain Research }
\end{array}
$$

Received: 14 November 2021

Accepted: 27 December 2021

Published: 24 January 2022

Citation:

Cheng C, Tabbara N, Cheng C and Shah V (2022) Intranasal Fentanyl for

Procedural Analgesia in Preterm Infants. Front. Pain Res. 2:815014.

doi: 10.3389/fpain.2021.815014

\section{Intranasal Fentanyl for Procedural Analgesia in Preterm Infants}

\author{
Charles Cheng ${ }^{1 \dagger}$, Najla Tabbara ${ }^{2 \dagger}$, Carol Cheng ${ }^{3}$ and Vibhuti Shah ${ }^{1 *}$ \\ ${ }^{1}$ Department of Pediatrics, Mount Sinai Hospital, Toronto, ON, Canada, ${ }^{2}$ Department of Pharmacy, Mount Sinai Hospital, \\ Toronto, ON, Canada, ${ }^{3}$ Department of Nursing, Mount Sinai Hospital, Toronto, ON, Canada
}

Background: Despite the availability of evidence-based analgesic strategies, neonatal pain management continues to be suboptimal. Intranasal (IN) fentanyl is an alternative pharmacotherapy for procedural pain in neonatal units. The objective was to evaluate the effectiveness and safety of IN fentanyl for procedural pain in preterm infants.

Methods: A retrospective cohort study was conducted in infants who received IN fentanyl between May 2019 and December 2020 at an academic neonatal intensive care unit. Main outcome measures were pain responses, physiological parameters before and up to 60 min after IN fentanyl administration, and adverse events. Paired $t$-test and analysis of variance were used to compare pain scores and physiological parameters, respectively.

Results: Thirteen infants received IN fentanyl on 22 occasions. Median (interquartile range [IQR]) gestational age and birthweight were $27(25,27.6)$ weeks and 850 (530, $1,030)$ grams, while median (IQR) post-menstrual age and weight were $30.9(28.9,32.9)$ weeks and 1,280 $(945,1,623)$ grams at the time of IN fentanyl administration. IN fentanyl was most used for lumbar puncture (55\%) followed by insertion of epicutaneo-caval catheters $(27 \%)$. There was a difference between the mean pre- and post-procedure Premature Infant Pain Profile scores of $1.3(95 \% \mathrm{Cl}=0.07,2.5 ; p=0.04)$. Physiological parameters did not differ before and up to 60 min post IN fentanyl administration ( $p$ > 0.05). Two adverse events (one apnea and one desaturation) were noted.

Conclusion: In our limited experience, IN fentanyl appears to be an alternative pharmacotherapy for procedural pain management in the absence of intravenous access in preterm infants.

Keywords: fentanyl, administration, intranasal, pain, procedural, preterm infants

\section{INTRODUCTION}

Infants admitted to the neonatal intensive care unit (NICU) experience as many as 7 to 17 painful procedures per day, with preterm infants $(<37$ weeks) at the highest risk of being exposed to greater numbers of painful procedures (1). Repeated or cumulative exposure to pain is associated with alteration in pain sensitivity and behavioral responses, sub-optimal brain development, and adverse neurodevelopmental outcomes (2,3). Despite these adverse consequences of pain and the availability of evidence-based non-pharmacological and pharmacological strategies to prevent and minimize pain, their use in the NICUs remains variable and suboptimal (4-7). Potential reasons for inadequate procedural analgesia include the perception that the pain is short-lived and concerns 
regarding the adverse effects of analgesics, especially opioids $(8,9)$. For infants with intravenous (IV) access, pharmacological strategies for management of moderate to severe procedural pain include the use of opioids such as morphine and fentanyl (57). In the absence of IV access, the intranasal (IN) route is an alternative mode to deliver opioids. It offers rapid and reliable systemic drug absorption with minimal discomfort to patients $(10,11)$. However, the literature around IN fentanyl use in the NICU setting remains scarce.

Four retrospective studies on the use of IN fentanyl in newborns and infants have been published thus far (12-15) (Table 1). Except for the study by Harlos et al. that prescribed IN fentanyl in the palliative care setting (12), the remaining studies evaluated its use for procedural pain in the NICU (13-15). The sample size in these studies ranged from 2 to 54 patients with mean/median gestational age (GA) at birth ranging from 26 to 35 weeks (13-15). Infants $<28$ weeks GA are considered extremely preterm while those between 28 and 32 weeks GA are considered very preterm. The most common procedures for IN fentanyl use were intubation and insertion of epicutaneo-caval catheters (1315). The dose of IN fentanyl ranged from 0.5 to $2 \mu \mathrm{g} / \mathrm{kg}(13-15)$ and was administered using a mucosal atomization device in the study by McNair et al. (13) or directly instilled into the infants' nares in the studies by Kaushal et al. and $\mathrm{Ku}$ et al. $(14,15)$. Sucrose was administered to all patients in conjunction with IN fentanyl in the study by McNair et al. (13) and IN midazolam was administered concurrently with IN fentanyl in almost half of the 67 events in the study by Kaushal et al. (14). No major adverse events were attributed to IN fentanyl use in the published studies (12-15).

While the administration of fentanyl via the IN route is currently not endorsed by neonatal and pediatric drug information resources (for infants and children $<10 \mathrm{~kg}$ ) or Canadian drug monographs (16-18), it has been used in the neonatal population for procedural pain and as part of palliative care (12-15). It offers several advantages including quick onset (within 5-10 min) and short duration of action, allowing for early targeted analgesia with fewer adverse effects and has been used widely in children in emergency settings $(19,20)$. In May 2019, a practice guideline on the use of IN fentanyl was added to the repertoire of pain management strategies in the NICU at our institution. The objective of our study was to describe our experience with IN fentanyl, specifically evaluating its effectiveness and safety profile.

\section{METHODS}

The study protocol was approved by the institutional Research Ethics Board. A retrospective chart review of infants who received IN fentanyl at Mount Sinai Hospital between May 2019 and December 2020 was undertaken. IN fentanyl could be used for procedural pain management and for palliative care when IV access was not established or analgesia was needed for a short period of time. Contraindications to its use include the presence of choanal atresia, nasal mucosal erosion, or epistaxis. Prior to implementation of the guideline, education sessions were held for healthcare professionals (nurses and medical personnel) regarding the indications for IN fentanyl and method of administration. Infants who received IN fentanyl were identified from the pharmacy database and included in the study. IN fentanyl was administered at a dose of $1.5 \mu \mathrm{g} / \mathrm{kg}$ using a mucosal atomization device which converts the fentanyl solution into $30 \mu \mathrm{m}$ particles. Using a quick push on the syringe plunger, the dose of fentanyl is dispersed in mist form into the nasal cavity, further enhancing its absorption into the vascular bed of the nasal mucosa. The size of the mucosal atomization device does not limit its usage in extremely preterm infants as it needs to be placed at the nares to allow the mist to be dispensed. After 5 min, a second dose could be administered based on the bedside nurse's clinical assessment (maximum two doses per procedure).

Data on infants who received IN fentanyl were collected from the hospital medical records using a pre-designed data collection form retrospectively. Data included demographics [GA at birth, birthweight (BW), sex, post-menstrual age (PMA), and weight] and type of respiratory support at the time of IN fentanyl administration. In addition, data on the type of procedure, number of attempts ( $>$ one) and number of IN fentanyl doses per procedure were collected. Effectiveness of IN fentanyl was assessed using the Premature Infant Pain Profile (PIPP) score by the bedside nurse. The pre-procedure PIPP score was recorded just before the administration of the first dose of IN fentanyl and commencement of the painful procedure while the postprocedure PIPP score was recorded within $30 \mathrm{~s}$ of successful completion of the procedure. The PIPP score ranges from 0 to 21. A PIPP score of $0-6$ suggests minimal or no pain, 7-12 indicates moderate pain and a score $\geq 13$ is interpreted as severe pain (21). The physiological parameters of heart rate, respiratory rate, oxygen saturation, and fraction of inspired oxygen $\left(\mathrm{FiO}_{2}\right)$ at baseline (just before IN fentanyl administration) and at prespecified intervals $(15,30,45$, and $60 \mathrm{~min})$ after IN fentanyl administration were also recorded. Adverse events were defined as apnea (cessation of breathing for $>20 \mathrm{~s}$ ), bradycardia (heart rate $<100$ beats/minute), desaturation (oxygen saturation $<$ $80 \%$ ), and chest wall rigidity and were monitored for $60 \mathrm{~min}$ after IN fentanyl administration.

Statistical analyses were performed using R statistical software version 4.0.4 (R Foundation for Statistical Computing, Vienna, Austria). Descriptive statistics were used to summarize patient demographic and clinical characteristics. Continuous data were reported as mean and standard deviation (SD) or median and interquartile range (IQR) as appropriate while categorical data were reported as number and percentage. Changes in pain scores and physiological parameters before and after IN fentanyl administration were compared using paired $t$-test and analysis of variance, respectively. All reported $p$-values are two-sided and $p$ $<0.05$ were considered statistically significant.

\section{RESULTS}

Thirteen infants received IN fentanyl on 22 occasions (Table 2). The median (IQR) GA at birth and BW was $27(25,27.6)$ weeks and $850(530,1,030)$ grams, respectively, and eight 
TABLE 1 | Summary of the literature.

\begin{tabular}{|c|c|c|c|}
\hline Study & Population, sample size and indication & Dose of IN fentanyl & Outcomes \\
\hline Harlos et al. (12) & $\begin{array}{l}\text { GA range }=24,41.7 \text { weeks; } \\
N=11 ; \\
\text { Palliative care }\end{array}$ & $\begin{array}{l}\text { Dose }=1-2 \mu \mathrm{g} / \mathrm{kg} \times 3 \text { doses within } \\
30 \mathrm{~min} \text { followed by reassessment }\end{array}$ & No adverse events reported \\
\hline McNair et al. (13) & $\begin{array}{l}\text { Mean }(\mathrm{SD}) \mathrm{GA}=31.8(4.1) \text { weeks; } \\
\text { Mean }(\mathrm{SD}) \mathrm{PMA}=35.6(4.6) \text { weeks; } \\
N=23 ; \\
\text { Procedural pain }\end{array}$ & $\begin{array}{l}\text { Dose }=1.5 \mu \mathrm{g} / \mathrm{kg} \\
5 \text { infants required a second dose }\end{array}$ & $\begin{array}{l}\text { PIPP scores Mean [SD]: Pre-procedure }=4.8 \\
\text { (3.2) During procedure }=4.3(1.8) \\
\text { Post-procedure = } 3.6(1.5) ; \\
\text { Cardio-respiratory depression in } 6 \text { patients (not } \\
\text { attributed to IN fentanyl) }\end{array}$ \\
\hline Kaushal et al. (14) & $\begin{array}{l}\text { Median }(\mathrm{IQR}) \mathrm{GA}=26(24.1,36.1) \text { weeks; } \\
\text { Median }(\mathrm{IQR}) \mathrm{PMA}=38.1(33.1,45.4) \text { weeks; } \\
N=54 ; \\
\text { Procedural pain and sedation }\end{array}$ & $\begin{array}{l}\text { Dose }=\text { Mean of } 1.46 \mu \mathrm{g} / \mathrm{kg} \text { (range } 0.5-2 \\
\mu \mathrm{g} / \mathrm{kg} \text { ); } \\
6 \text { procedures required a second dose; } \\
\text { IN midazolam was co-administered in } 32 \\
\text { cases }\end{array}$ & No adverse events attributed to IN fentanyl \\
\hline Ku et al. (15) & $\begin{array}{l}\text { Mean } \mathrm{GA}=35 \text { weeks; } \\
N=2 ; \\
\text { Procedural pain }\end{array}$ & $\begin{array}{l}\text { Dose }=1-2 \mu \mathrm{g} / \mathrm{kg} \\
\text { No second dose administered }\end{array}$ & No adverse events attributed to IN fentanyl \\
\hline
\end{tabular}

GA, gestational age; IQR, interquartile range; IN, intranasal; N, number of patients; PIPP, Premature Infant Pain Profile; PMA, post-menstrual age; SD, standard deviation.

TABLE 2 | Clinical characteristics of patients at IN fentanyl administration.

\begin{tabular}{lc}
\hline Variable & $\begin{array}{c}\text { Total events } \\
(\mathbf{N}=\mathbf{2 2})\end{array}$ \\
\hline Post-menstrual age (weeks) & $30.9(28.9,32.9)$ \\
Weight at the time of IN fentanyl administration & $1,280(945,1,623)$ \\
(grams) & \\
Type of respiratory support & $5(23 \%)$ \\
Invasive & $17(77 \%)$ \\
Non-invasive & $12(55 \%)$ \\
Type of procedure & $6(27 \%)$ \\
Lumbar puncture & $4(18 \%)$ \\
Epicutaneo-caval catheter insertion & $4(18 \%)$ \\
Endotracheal intubation & \\
Second dose of IN fentanyl administered &
\end{tabular}

Results are presented as median (interquartile range) or number (percentage). IN, intranasal.

(62\%) infants were male. For 17 events (77\%), infants were receiving various forms of non-invasive ventilatory support including continuous positive airway pressure, non-invasive positive pressure ventilation, and non-invasive neutrally adjusted ventilatory assist. IN fentanyl was most used for lumbar puncture (55\%) followed by insertion of epicutaneo-caval catheters (27\%) and endotracheal intubation (18\%). A second dose of IN fentanyl was administered in three infants (four events [18\%]) at the discretion of the bedside nurse for agitation.

The mean (SD) pre-and post-procedure PIPP scores were 5.4 (2.4) and 4.2 (1.6), respectively. There was a statistically significant difference in the mean PIPP score of 1.3 (95\% CI $0.07,2.5 ; p=0.04)$. Physiological parameters before and up to $60 \mathrm{~min}$ post-administration of IN fentanyl were not significantly different $(p>0.05)$ (Figure 1). Of the 22 events reported, in 10 events the procedure had to be repeated more than once (lumbar puncture $[n=7]$, epicutaneo-caval catheter insertion [ $n$ $=2]$, and endotracheal intubation $[n=1])$. The post-procedure PIPP score was always recorded after successful completion of the procedure.

Two adverse events were recorded. One infant weighing $710 \mathrm{~g}$ with PMA of 27.7 weeks had respiratory deterioration with increasing $\mathrm{FiO}_{2}$ and hence a decision was made to intubate. Two minutes after IN fentanyl administration, the infant had an apneic episode requiring positive pressure ventilation. The second infant weighing $880 \mathrm{~g}$ with PMA of 26.9 weeks needed a lumbar puncture for suspected sepsis. This infant had an episode of desaturation $45 \mathrm{~min}$ after IN fentanyl administration and required increase in oxygen concentration briefly. There were no reports of bradycardia or chest wall rigidity.

\section{DISCUSSION}

In this small study of preterm infants, we were able to demonstrate the effectiveness of IN fentanyl in reducing procedural pain as assessed by PIPP scores. Our practice consisted of administration of IN fentanyl as the only analgesic without the use of adjuncts such as sucrose or IN midazolam. Our results are consistent with the PIPP scores from the study by $\mathrm{McNair}$ et al. in which the mean (SD) pre-procedure score was 4.8 (3.2) and the post-procedure score was 3.6 (1.5) (13). Despite exhibiting physiological and behavioral responses to stress and painful stimuli in the NICU environment, preterm infants have diminished mechanisms to modulate pain compared to older infants (22-24). Other potential reasons for lower PIPP scores may include the inability of critically ill preterm infants to mount responses, and inaccurate pain assessments due to health care professionals' potential lack of knowledge and understanding of neonatal pain or inappropriate use of the PIPP tool (9, 2528). There were no differences noted in physiological parameters 

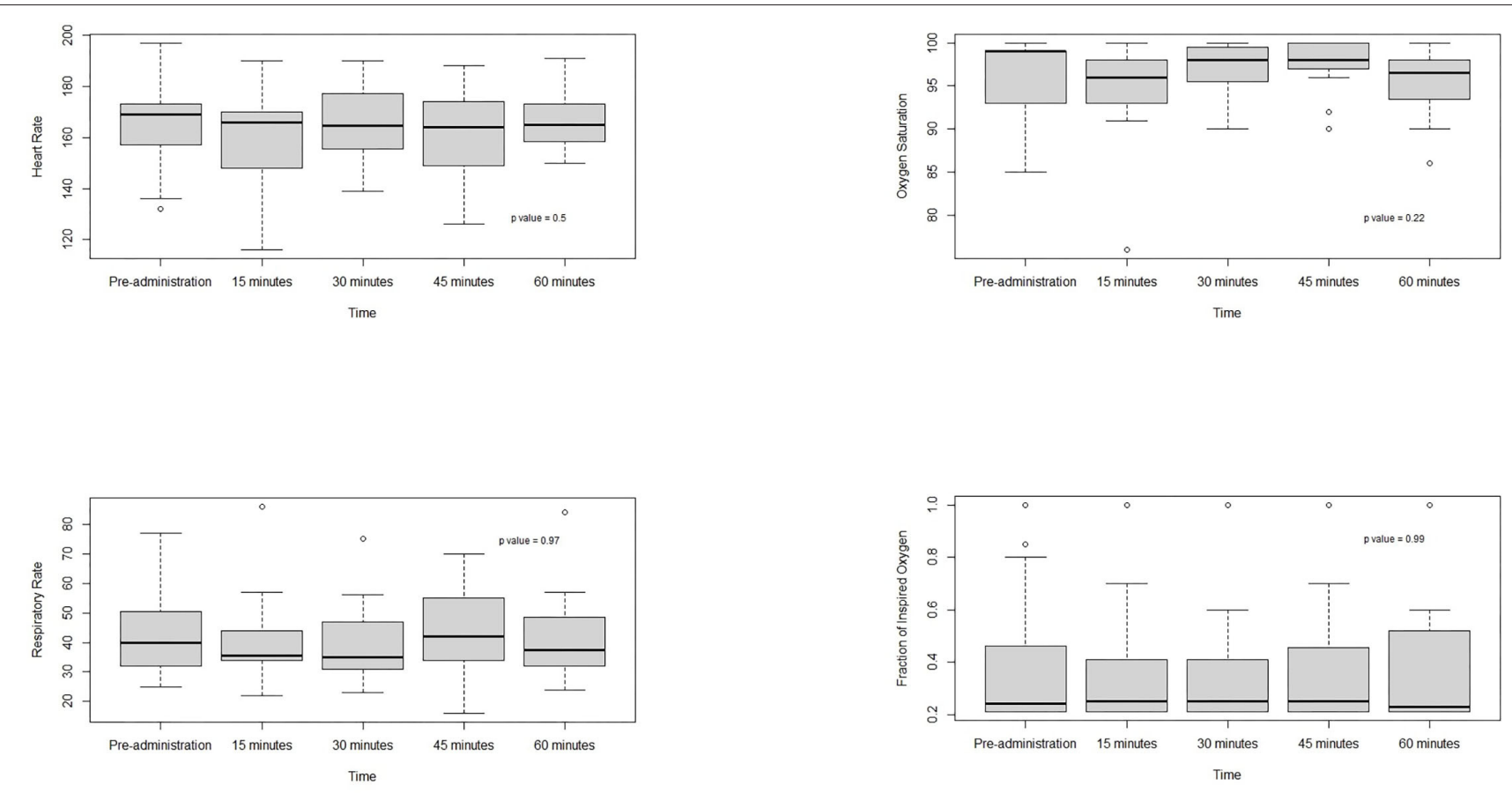

FIGURE 1 | Physiological parameters before and up to 60 min after IN fentanyl administration.

up to $60 \mathrm{~min}$ after its administration and there were no major adverse events.

In contrast to infants in the NICU, IN fentanyl has been welladopted in the emergency department when children present with moderate to severe pain secondary to fractures or burns. In the non-neonatal pediatric population, its effectiveness is wellestablished with an improved safety profile compared to IV opioid administration $(20,29)$. As an alternative route of drug administration, IN fentanyl is a highly lipid soluble medication with rapid absorption by the highly vascular nasal mucosa with the potential of being transported directly into the cerebrospinal fluid $(30,31)$. It has an approximate bioavailability of $70 \%$ and avoids first pass metabolism by the liver (32). It provides timely analgesia without delaying procedures and decreases the requirement of invasive IV line placements which may be difficult to secure. Considering its advantages and ease of administration, IN fentanyl is an appealing pharmacological alternative in the management of neonatal procedural pain. The results of our study add to the growing body of literature supporting IN fentanyl use in the preterm population.

Limitations of our study include a small sample size over a 20-month period, absence of a control group, and potential risk for selection bias as not all eligible patients may have received the therapy. We aimed to reduce this bias by providing education to healthcare professionals regarding infants who would benefit from this intervention but our sample may not be fully representative of our NICU patients even though our findings are consistent with other studies of IN fentanyl in the neonatal population. Another limitation is the timing of the post-procedure PIPP score in infants who received two doses of IN fentanyl. The time interval between the second dose and post-procedure PIPP score was not captured. We did not assess the perception (beliefs and attitudes) of healthcare professionals regarding the use of IN fentanyl for procedural pain and this should be evaluated in future studies as this information may be relevant for its adoption in clinical practice. Engagement and satisfaction from parents and caregivers should also be considered when assessing IN fentanyl use in patients in the NICU.

Randomized controlled trials are considered the gold standard to assess the effectiveness and safety of an intervention and future research on IN fentanyl should be undertaken using this study design with adequate sample size. Pharmacokinetic and pharmacodynamic studies on IN fentanyl in preterm infants will also be beneficial to optimize drug dosing and delivery and minimize adverse effects. Qualitative studies assessing healthcare providers' perceptions, facilitators, and barriers to IN drug administration should be examined as physicians and nurses play a key role in pain management. While awaiting further research, IN fentanyl provides an alternative therapeutic option to manage procedural pain in neonates when IV access is not available.

\section{CONCLUSION}

IN fentanyl appears to be an alternative pharmacotherapy for procedural pain management in the absence of IV access in preterm infants. 


\section{DATA AVAILABILITY STATEMENT}

The data analyzed in this study is subject to the following licenses/restrictions. The dataset for this study is not available without institutional Research Ethics Board approval. Data were collected by chart review using medical records from Mount Sinai Hospital, Toronto, Ontario, Canada. Requests to access these datasets should be directed to Vibhuti Shah, Vibhuti.Shah@sinaihealth.ca.

\section{ETHICS STATEMENT}

The studies involving human participants were reviewed and approved by Mount Sinai Hospital Research Ethics

\section{REFERENCES}

1. Cruz MD, Fernandes AM, Oliveira CR. Epidemiology of painful procedures performed in neonates: a systematic review of observational studies. Eur $J$ Pain. (2016) 20:489-98. doi: 10.1002/ejp.757

2. Brummelte S, Grunau RE, Chau V, Poskitt KJ, Brant R, Vinall J, et al. Procedural pain and brain development in premature newborns. Ann Neurol. (2012) 71:385-96. doi: 10.1002/ana.22267

3. Walker SM. Long-term effects of neonatal pain. Semin Fetal Neonatal Med. (2019) 24:101005. doi: 10.1016/j.siny.2019.04.005

4. Harrison D, Loughnan P, Johnston L. Pain assessment and procedural pain management practices in neonatal units in Australia. J Paediatr Child Health. (2006) 42:6-9. doi: 10.1111/j.1440-1754.2006.00781.x

5. Carbajal R, Rousset A, Danan C, Coquery S, Nolent P, Ducrocq S, et al. Epidemiology and treatment of painful procedures in neonates in intensive care units. JAMA. (2008) 300:60-70. doi: 10.1001/jama.300.1.60

6. Johnston C, Barrington KJ, Taddio A, Carbajal R, Filion F. Pain in Canadian NICUs: have we improved over the past 12 years? Clin J Pain. (2011) 27:22532. doi: 10.1097/AJP.0b013e3181fe14cf

7. Lago P, Frigo AC, Baraldi E, Pozzato R, Courtois E, Rambaud J, et al. Sedation and analgesia practices at Italian neonatal intensive care units: results from the EUROPAIN study. Ital J Pediatr. (2017) 43:26. doi: 10.1186/s13052-017-0343-2

8. Mehrnoush N, Ashktorab T, Heidarzadeh M, Momenzadeh S. Knowledge and attitude of personnel, key factors in implementation of neonatal pain management in NICU: a qualitative study. J Clin Diagn Res. (2017) 11: SC059. doi: $10.7860 / \mathrm{JCDR} / 2017 / 26290.10851$

9. Peng NH, Lee MC, Su WL, Lee CH, Chen CH, Chang YC, et al. Knowledge, attitudes and practices of neonatal professionals regarding pain management. Eur J Pediat. (2021) 180:99-107. doi: 10.1007/s00431-020-03718-0

10. Grassin-Delyle S, Buenestado A, Naline E, Faisy C, Blouquit-Laye S, Couderc LJ, et al. Intranasal drug delivery: an efficient and non-invasive route for systemic administration: focus on opioids. Pharmacol Ther. (2012) 134:36679. doi: 10.1016/j.pharmthera.2012.03.003

11. Pacifici GM. Clinical pharmacology of fentanyl in preterm infants. A review. Pediatr Neonatol. (2015) 56:143-8. doi: 10.1016/j.pedneo.2014.06.002

12. Harlos MS, Stenekes S, Lambert D, Hohl C, Chochinov HM. Intranasal fentanyl in the palliative care of newborns and infants. J Pain Symptom Manage. (2013) 46:265-74. doi: 10.1016/j.jpainsymman.2012.07.009

13. McNair C, Graydon B, Taddio A. A cohort study of intranasal fentanyl for procedural pain management in neonates. Paediatr Child Health. (2018) 23:e170-5. doi: 10.1093/pch/pxy060

14. Kaushal S, Placencia JL, Maffei SR, Chumpitazi CE. Intranasal fentanyl use in neonates. Hosp Pharm. (2020) 55:126-9. doi: 10.1177/0018578719828335

15. Ku LC, Simmons C, Smith PB, Greenberg RG, Fisher K, Hornik CD, et al. Intranasal midazolam and fentanyl for procedural sedation and analgesia in infants in the neonatal intensive care unit. J Neonatal Perinatal Med. (2019) 12:143-8. doi: 10.3233/NPM-17149
Board. Written informed consent from the participants' legal guardian/next of kin was not required to participate in this study in accordance with the national legislation and the institutional requirements.

\section{AUTHOR CONTRIBUTIONS}

$\mathrm{NT}, \mathrm{CaC}$, and VS: study design. $\mathrm{ChC}$ and $\mathrm{CaC}$ : data collection. NT and VS: statistical calculations and analyses. $\mathrm{ChC}$ and NT: drafting of the manuscript. ChC, NT, CaC, and VS: critical review and editing of the manuscript. All authors contributed to the article and approved the final manuscript.

16. Pediatric \& Neonatal Lexi-Drugs. Lexicomp Inc. (2021). Available online at: https://online.lexi.com

17. Micromedex NeoFax and Pediatrics. IBM Watson Health (2021). Available online at: https://www.micromedexsolutions.com

18. Drug Product Database. Government of Canada (2021). Available online at: https://www.canada.ca/en/health-canada/services/drugs-health-products/ drug-products/drug-product-database.html

19. Borland ML, Jacobs I, Geelhoed G. Intranasal fentanyl reduces acute pain in children in the emergency department: a safety and efficacy study. Emerg Med. (2002) 14:275-80. doi: 10.1046/j.1442-2026.2002.00344.x

20. Mudd S. Intranasal fentanyl for pain management in children: a systematic review of the literature. J Pediatr Health Care. (2011) 25:316-22. doi: 10.1016/j.pedhc.2010.04.011

21. Stevens B, Johnston C, Petryshen P, Taddio A. Premature infant pain profile: development and initial validation. Clin J Pain. (1996) 12:1322. doi: 10.1097/00002508-199603000-00004

22. Franck LS, Miaskowski C. Measurement of neonatal responses to painful stimuli: a research review. J Pain Symptom Manage. (1997) 14:34378. doi: 10.1016/s0885-3924(97)00222-4

23. Hall W and Anand KJS. Physiology of pain and stress in the newborn. Neoreviews. (2005) 6:e61-8. doi: 10.1542/neo.6-2-e61

24. Fitzgerald M. The development of nociceptive circuits. Nat Rev Neurosci. (2005) 6:507-20. doi: 10.1038/nrn1701

25. Committee on Fetus and Newborn and Section on Anesthesiology and Pain Medicine. Prevention and management of procedural pain in the neonate: an update. Pediatrics. (2016) 137:e20154271. doi: 10.1542/peds.2015-4271

26. Ganguly A, Bhadesia PJ, Phatak AG, Nimbalkar AS, Nimbalkar SM. Pain profile of premature infants during routine procedures in neonatal intensive care: an observational study. J Family Med Prim Care. (2020) 9:151721. doi: 10.4103/jfmpc.jfmpc_1033_19

27. Stevens B, Riahi S, Cardoso R, Ballantyne M, Yamada J, Beyene $\mathrm{J}$, et al. The influence of context on pain practices in the NICU: perceptions of health care professionals. Qual Health Res. (2011) 21:75770. doi: 10.1177/1049732311400628

28. Cong X, Delaney C, Vazquez V. Neonatal nurses' perceptions of pain assessment and management in NICUs: a national survey. Adv Neonatal Care. (2013) 13:353-60. doi: 10.1097/ANC.0b013e31829d62e8

29. Kusre SR. Towards evidence based emergency medicine: best BETs from the Manchester Royal Infirmary. Bet 4: is intranasal fentanyl better than parenteral morphine for managing acute severe pain in children? Emerg Med J. (2011) 28:1077-8. doi: 10.1136/emermed-2011-200892

30. Committee on Drugs. Alternative routes of drug administrationadvantages and disadvantages (subject review). Pediatrics. (1997) 100:143-52. doi: 10.1542/peds.100.1.143

31. Wolfe TR, Braude DA. Intranasal medication delivery for children: a brief review and update. Pediatrics. (2010) 126:532-7. doi: 10.1542/peds.2010-0616

32. Cole J, Shepherd $M$, Young $P$. Intranasal fentanyl in 1-3year-olds: a prospective study of the effectiveness of intranasal 
fentanyl as acute analgesia. Emerg Med Australas.

21:395-400. doi: 10.1111/j.1742-6723.2009.01216.x

(2009)

Conflict of Interest: The authors declare that the research was conducted in the absence of any commercial or financial relationships that could be construed as a potential conflict of interest.

Publisher's Note: All claims expressed in this article are solely those of the authors and do not necessarily represent those of their affiliated organizations, or those of the publisher, the editors and the reviewers. Any product that may be evaluated in this article, or claim that may be made by its manufacturer, is not guaranteed or endorsed by the publisher.

Copyright (c) 2022 Cheng, Tabbara, Cheng and Shah. This is an open-access article distributed under the terms of the Creative Commons Attribution License (CC BY). The use, distribution or reproduction in other forums is permitted, provided the original author(s) and the copyright owner(s) are credited and that the original publication in this journal is cited, in accordance with accepted academic practice. No use, distribution or reproduction is permitted which does not comply with these terms. 